\section{Abetting Emigration of Canada's Nurses and Doctors}

\author{
Mark Bernstein
}

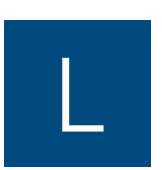

ast year an article appeared in Healthcare Quarterly attempting to analyze and understand reasons nurses emigrate from Canada to the United States, specifically North Carolina (Pink et al. 2004). An introduction to the article appeared unsympathetic to this situation (Pringle 2004). I recently came across the Spring issue of a Canadian-based publication whose mission, as printed in the publication, is "to provide healthcare professionals with job opportunities" among other things. Of the eight large glossy pages constituting the publication, almost two (25\%) were devoted to advertisements attracting Canadian nurses to other countries. There were four ads (including one full-page) extolling the virtues of nursing in the United States and one attracting nurses to work in the United Kingdom. I e-mailed the publisher and the editor to gently challenge them on the ethics of doing this but received no response.

"Poaching" of healthcare professionals is an old but evergrowing problem, impeding the development of better healthcare in a number of societies, most notably in many developing countries. Singh et al. (2003) articulately analyzed the ethics of this practice in the nursing profession and denounced the practice of developed countries recruiting nurses from developing countries. They also argued that developing nations are not doing enough to address the factors that precipitate nurse migration (Singh et al. 2003). (Although Canada is not a developing country, we can fairly be accused of not doing enough to prevent our own nursing "brain drain.") Patel (2003) explored the problem, specifically focusing on the recruitment of doctors from India and other developing countries to the UK after they have completed fellowship training in the UK. He suggested some specific requirements for ethical recruitment of doctors from developing countries (Patel 2003). In some situations, leaders in developing countries have formally asked developed countries, including Canada, to recruit fewer of their healthcare professionals (Spurgeon 2001).

The Canadian healthcare system is one of the last not-forprofit socialized, one-tiered systems in the world. We are all aware of its shortcomings, such as inappropriately long waits for diagnostic procedures such as magnetic resonance imaging, and for elective surgical procedures such as knee replacement. We are also all aware that, by and large, it is the most humane, fair and efficient system in the world. A recent full-length article in the New York Times Magazine, speculating on American healthcare reform, referred to the Canadian system a number of times, mostly favourably (Lowenstein 2005).
Canada and the US are both highly developed countries, so asymmetry in quality of healthcare is not a major issue in drawing healthcare providers from one country to the other. However, there is asymmetry in remuneration, in that nurses attracted to the US from Canada can expect bigger signing bonuses and higher salaries. Additionally, there is often an improvement in personal lifestyle such as weather, improved educational opportunities (as many American hospitals support nurses' pursuit of advanced education) and other factors (Pink et al. 2004; Pringle 2004). The differential between incomes of Canadian and American doctors, especially specialists, is even more substantial than the differential in nurses' salaries. Therefore, arguably the main incentive that attracts healthcare providers from Canada to the US is similar to (though scaleddown from) the strong incentive that draws healthcare providers from developing to developed countries.

Many of these factors cannot be changed overnight. In spite of that, many Canadians would still prefer to live and work in Canada. Therefore, the brain drain from Canada to the US continues at a steady but limited rate, which does not cripple our universities and hospitals, for example, but it certainly poses ongoing challenges to these and other institutions within our society, which has only one-tenth the human resources to draw on compared to the US. This challenge is arguably greater within the nursing profession than with any other identifiable group of professionals in our country.

Canada is a land of opportunity, and no one would ever stand in the way of people seeking a better or more fulfilling life, even if that takes them away from Canada. But my simple question is this: Should Canadians be so tolerant, unworried and even smug about Canada's future that we actually facilitate this brain drain? Instead of making it ridiculously simple for nurses and doctors to leave, why don't we make it easier for them to stay? Various half-hearted strategies have been employed to do this over the years, and these initiatives have been incompletely and/or only intermittently successful. Maybe if we try harder we can do better at keeping our valued healthcare professionals within the best healthcare system in the world, and in a country where most of them would likely prefer to remain. This message is directed squarely at government, hospital administrators and others in a position to make the material changes needed to stop the brain drain of nurses and doctors to the US. A financial commitment to secure the future of our healthcare system seems like an investment with positive and crucial benefit to this particular warrior in the healthcare trenches.

Mark Bernstein MD, MHSc, FRCSC is a Professor in the Department of Surgery, University of Toronto Division of Neurosurgery based at the Toronto Western Hospital site of the University Health Network. 


\section{Just the Facts ...}

\section{References}

Lowenstein, R. 2005, March 13. "The Quality Cure?" New York Times Magazine pp. 46-51.

Patel, V. 2003. "Recruiting Doctors from Poor Countries: The Great Brain Robbery?” British Medical Journal 327: 926-28.

Pink, G.H., L.M. Hall and P. Leatt. 2004. "Canadian-Trained Nurses in North Carolina.” Healthcare Quarterly 7: Suppl. 2-11.

Pringle, D. 2004. Guest Adversaria. Healthcare Quarterly 7: Suppl. 1.

Singh, J.A., B. Nkala, E. Amuah, N. Mehta and A. Ahmad. 2003. "The Ethics of Nurse Poaching from the Developing World." Nursing Ethics 10: 667-71.

Spurgeon, D. 2001. "Canada Asked to Recruit Fewer South African Doctors." British Medical Journal 322: 189.

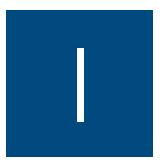

very much appreciated the piece in the Healthcare Quarterly (8(1):89) "Primary Healthcare: The All-TooQuiet-Revolution in Waiting."

My problem is that the examples quoted are isolated. The Use Health Centre's project in Halifax addresses one narrow topic. The Hamilton Project also addresses only specifically mental health and nutrition. They are not a broad range of services. They are very directed to narrow targets. The BC Nurse Line answered approximately 16 calls for each physician visit that was preempted. I doubt that this is a very efficient system. Even as a specialist, I only receive $\$ 25$ for a visit. I doubt very much that a nurse-line service can handle telephone calls at $\$ 1.61$ per telephone call. Maybe the Saskatchewan system works better with a range of healthcare professionals. I do agree that the system described in Northern England may be better. I, as a specialist, would very much like to have electronic health records system with a smart card containing all information on a patient but neither the privacy advocates nor the cost of implementation make such an undertaking feasible.

I am very strongly in favour of a nurse practitioner program and have supported them very strongly in Cornwall. My concern is not displacement of physicians.

You also indicated that change seems faster and more effective across the ocean but the most important part that you omitted is the fact that in Canada we train and have far fewer physicians per population than exist in Europe. An integrated system still demands physician participation and a sudden transition from our patient-oriented system to a multidisciplinary team work requires stepwise establishment. That would dislocate existing physicians and therefore, at least temporarily, services would be curtailed rather than initially expanded. No physician is willing to participate in further curtailment of services even if the horizon is brighter in the future. Maybe governments should not have cut back on medical school enrolment in Ontario 15 years ago but implementation of a changing system is temporarily disruptive which would potentially lead to disaster during the implementation stage, even if the long-term effects are beneficial.

- Thomas Baitz, MD, FRCP(C),

Internal Medicine - Nephrology - Cardiology, Cornwall, ON

\section{Crank up the Heat}

hilly workers not only make more errors

but cooler temperatures could increase a worker's hourly labour cost by $10 \%$, estimates Alan Hedge, PhD, professor of design and environmental analysis and director of Human Factors and Ergonomics Laboratory at Cornell University, in Ithaca, NY.

When temperatures were increased in an office from 68 to 77 degrees Fahrenheit during a month-long study, typing errors fell by $44 \%$ and typing output jumped $150 \%$. Dr. Hedge's study explored the link between changes in the physical environment and work performance.

In the study, which was conducted at Insurance Office of America's headquarters in Orlando, FL, each of nine workstations was equipped with a miniature personal environment-sensor for sampling air temperature every 15 minutes. The researchers recorded the amount of time that employees keyboarded and the amount of time they spent making error corrections. Dr. Hedge used a new research approach employing software that can synchronize a specific indoor environmental variable - in this case temperature - with productivity.

"At 77 degrees Fahrenheit, the workers were keyboarding $100 \%$ of the time with a $10 \%$ error rate, but at 68 degrees, their keying rate went down to $54 \%$ of the time with a $25 \%$ error rate," explained Dr. Hedge. "Temperature is certainly a key variable that can impact performance."
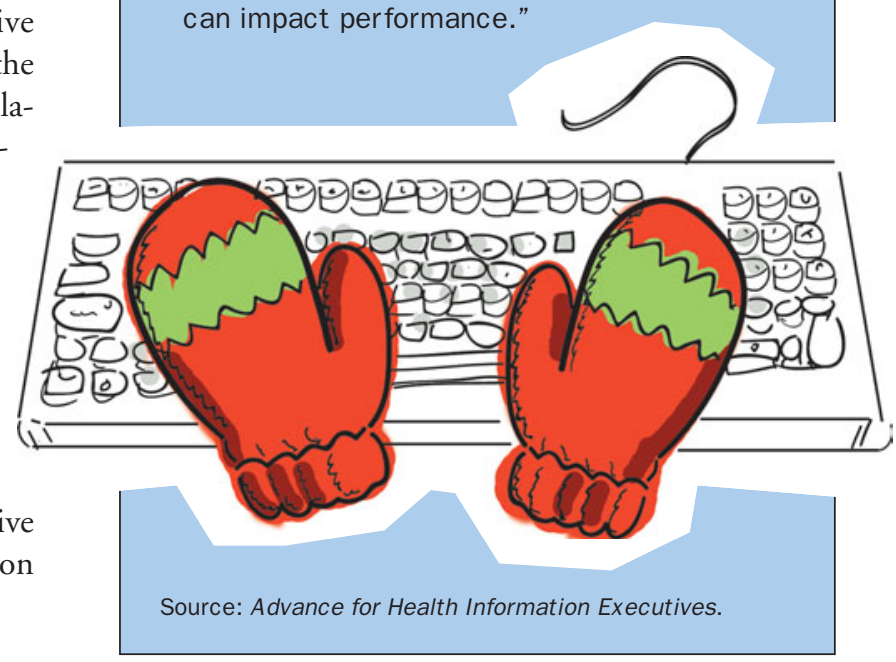


\section{Mythbuster}

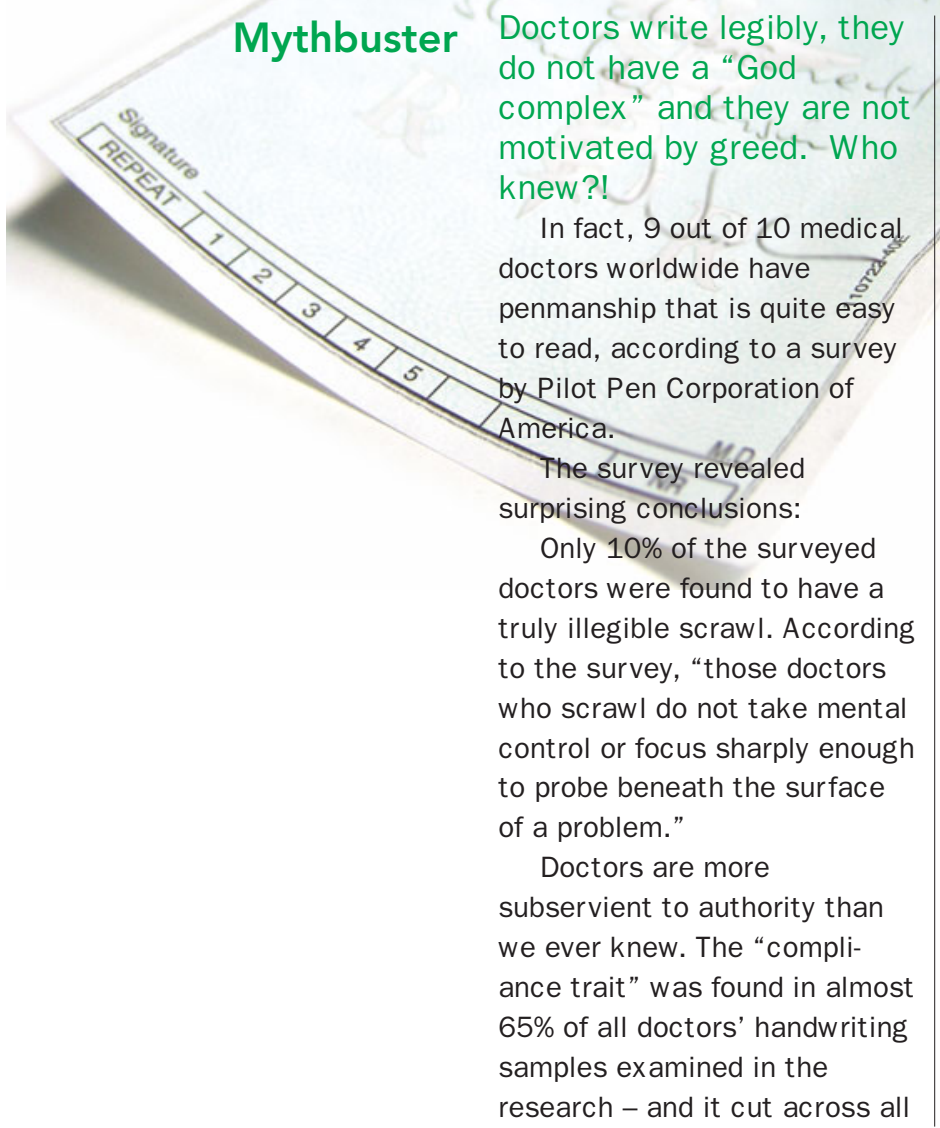

boundaries of nationality or medical specialty. Those doctors demonstrated thought patterns indicating their willingness to yield to authority, accepting information with little or no effort to analyze or investigate it.

Not all MDs pursue Porsches, 10 a.m. tee times and the almighty dollar. Their handwriting actually indicates that spiritual and intellectual needs outweigh the average doctor's desire for material goods. The handwriting traits for greediness ("initial hooks" at the beginning of letters) are just not there.

Many MDs are more comfortable talking ... and not listening. Many handwriting samples demonstrate this trait - by the open o's and a's within words.

Among other findings about physicians from the Pilot Pen/Graphology Consulting
Group handwriting report are the characteristics of medical specialists:

- Cardiologists - fast thinkers, open-minded, positive high energy.

- Neurologists - forward thinkers, quick, interested, intuitive and "elegant."

- Orthopedic surgeons surprisingly, only $15 \%$ display handwriting signs that indicate manual dexterity.

- Male OB/GYNs - the most depressed, stressed and disheartened among all specialties. When asked why, many pointed to greedy, ungrateful families and aggressive malpractice lawyers.

- Female OB/GYNs optimistic, energetic.

- Anesthesiologists - clear thinking, objective, not impulsive - good traits for the operating room.
Weird

Accidents

That Put Us in Hospitals
In the United Kingdom, more than 50 people were admitted to hospital after being struck by lightning in the past year and two people were injured by centipedes. These are just some of the reasons people went to hospital as revealed on a list of

weird and wonderful accidents in the last 12 months. No fewer than 22 suffered mishaps involving nightwear - either setting them alight by accident or getting tangled up and nearly strangled.

The Department of Health data also included people requiring hospital treatment in the United Kingdom for accidents that happened overseas.

There were nearly a million people seen by emergency hospital staff in the 12 months to April 2004.

Six had been stung by scorpions, along with the 451 stung by hornets and 24 bitten by rats.

The house was no haven, with nine needing treat- ment for accidents with their beds and 22 exposed to "ignition or melting of nightwear" usually due to cigarettes or faulty electric blankets.

Other unusual problems included nine people who experienced "accidental suffocation and strangulation in bed" and a child who attended hospital after a "prolonged stay in a weightless environment."

Among more unusual accidents, those involving tools such as hammers affected 4,115 people, while around 2,000 more fell out of trees. The data for admissions also included 138 people who had foreign objects left in their bodies following surgery. Source: Yahoo. 